\title{
Real time cardiac MRI and its clinical usefulness in arrhythmias and wall motion abnormalities
}

\author{
Christina Unterberg-Buchwald ${ }^{1,2^{*}}$, Martin Fasshauer ${ }^{2}$, Jan M Sohns ${ }^{2}$, Wieland Staab ${ }^{2}$, Andreas Schuster ${ }^{1}$, Dirk Voit ${ }^{3}$, \\ Johannes T Kowallick', Michael Steinmetz ${ }^{4}$, Jens Frahm ${ }^{3}$, Joachim Lotz ${ }^{2}$
}

From 17th Annual SCMR Scientific Sessions

New Orleans, LA, USA. 16-19 January 2014

\section{Background}

Analysis of cardiac function in patients with arrhythmias is very limited or nearly impossible in ECG synchronized cine acquisitions with balanced SSFP. A real-time method at $1.5 \mathrm{~T}$ with SSFP contrast was used to show that this method is superior for image quality and analysis of ventricular function in a subset of patients with atrial fibrillation and AV-Block.

\section{Methods}

Radial gradient-echo sequences with fully balanced SSFP gradients and at least 15-fold undersampling (real-time SSFP, RT) and conventional ECG-synchronized cine SSFP CMR (Cine) was used on a $1.5 \mathrm{~T}$ scanner system. Patients who had permanent arrhythmias (most often atrial fibrillation, AA; $\mathrm{n}=8$ ) or wall motion abnormalities (WMA; $\mathrm{n}=3$ ) were scanned in the standard views and compared to patients in sinus rhythm $(\mathrm{SR} ; \mathrm{n}=21)$ without wall motion abnormalities. Image reconstruction of RT was performed offline by regularized nonlinear inversion. Quality (IQ) of scan was detected using an image quality score (ranging from $0=$ no diagnostic quality to $1=$ reduced diagnostic quality, $2=$ many artifacts, 3 = some artifacts, and $4=$ optimal diagnostic quality). Cardiac function was analyzed using a semiautomatic contour detection ( $\mathrm{Q}$ mass, Medis, NL) applied to 5 consecutive baets in RT and Cine avering data of 10-12 beats. All analysis was done by two blinded observers ( 3 and 8 years experience of CMR evaluation).

\section{Results}

IQ was comparable for Cine and RT SSFP in patients with WMA or patients in sinus rhythm without WMA given in Table 1. However, IQ was significantly better

Table 1

\begin{tabular}{ccccc}
\hline Views for IQ and quantitative parameters & Patient groups & Number of views & RT & Cine \\
\hline Short axis base (IQ) & AA & 16 & $3.94 \pm 0.25^{*}$ & $2.75 \pm 0.68$ \\
& WMA & 6 & $4.00 \pm 0.00$ & $4.00 \pm 0.00$ \\
& SR & 42 & $3.62 \pm 0.54$ & $3.95 \pm 0.22$ \\
Short axis mid (IQ) & AA & 16 & $3.81 \pm 0.40 *$ & $2.69 \pm 0.60$ \\
& WMA & $6.67 \pm 0.5$ & $4.00 \pm 0.00$ \\
& SR & 42 & $3.48 \pm 0.67$ & $3.93 \pm 0.26$ \\
\hline Short axis apex (IQ) & AA & 16 & $3.81 \pm 0.40 *$ & $2.19 \pm 0.91$ \\
& WMA & 6 & $3.00 \pm 1.26$ & $3.50 \pm 0.55$ \\
Enddiastolic volume $[\mathrm{ml}]$ & SR & 42 & $3.07 \pm 0.97$ & $3.70 \pm 0.55$ \\
\hline & AA & 16 & $55.15 \pm 10.17$ & $36.80 \pm 20.13$ \\
Endsystolic volume $[\mathrm{ml}]$ & SRA & 3 & $52.39 \pm 3.91$ & $43.10 \pm 6.73$ \\
& AA & 16 & $47.50 \pm 12.70$ & $51.32 \pm 18.4$ \\
& WMA & 16 & $32.30 \pm 13.11$ & $21.60 \pm 16.50$ \\
& SR & 3 & $30.50 \pm 9.80$ & $24.10 \pm 6.86$ \\
\hline
\end{tabular}

${ }^{1}$ Cardiology, University Clinic Goettingen, Goettingen, Germany

Full list of author information is available at the end of the article 
Table 1 (Continued)

\begin{tabular}{ccccc}
\hline Beat volume $[\mathrm{ml}]$ & AA & 16 & $22.83 \pm 6.30$ & $15.20 \pm 6.20$ \\
& WMA & 3 & $21.90 \pm 8.50$ & $19.00 \pm 1.27$ \\
& SR & 16 & $22.37 \pm 5.30$ & $29.84 \pm 16.7$ \\
\hline Ejection fraction [\%] & AA & 16 & $43.50 \pm 15.10$ & $46.30 \pm 16.10$ \\
& WMA & 3 & $41.70 \pm 16.70$ & $45.00 \pm 6.90$ \\
& SR & 16 & $50.00 \pm 12.20$ & $57.90 \pm 12.50$ \\
\hline
\end{tabular}

${ }^{*} \mathrm{p}<0.001$ RT vs Cine

for RT compared to Cine in all three short axis in patients with arryhthmias. Functional parameters showed no significant differences, however there was a trend to lower values for enddiastolic, endsystolic and beat volumes for Cine (10-12 beats) compated to RT (5 consecutive beats) in RT.

\section{Conclusions}

RT cardiac MRI is a robust method with high image quality that has the potential to allow functional analysis of sequences in patients with arrhythmias that are often difficult or impossible to analyze by cine SSFP.

\section{Funding}

No funding.

\section{Authors' details}

${ }^{1}$ Cardiology, University Clinic Goettingen, Goettingen, Germany. ${ }^{2}$ Institute of Diagnostic and Interventional Radiology, University Clinic Goettingen,

Goettingen, Germany. ${ }^{3}$ Biomedizinische NMR Forschungs $G m b H$, Max-PlanckInstitut für biophysikalische Chemie, Goettingen, Germany. ${ }^{4}$ Pediatric

Cardiology and Intensive Care, University Clinic Goettingen, Goettingen,

Germany.

Published: 16 January 2014

\section{Submit your next manuscript to BioMed Central} and take full advantage of:

- Convenient online submission

- Thorough peer review

- No space constraints or color figure charges

- Immediate publication on acceptance

- Inclusion in PubMed, CAS, Scopus and Google Scholar

- Research which is freely available for redistribution

Submit your manuscript at www.biomedcentral.com/submit
C Biomed Central 